\title{
Second primary malignancies in patients with male breast cancer
}

\author{
K Hemminki, 1,2, G Scélo ${ }^{3}$, P Boffetta ${ }^{3}$, L Mellemkjaer ${ }^{4}$, E Tracey ${ }^{5}$, A Andersen ${ }^{6}$, DH Brewster ${ }^{7}$, E Pukkala ${ }^{8}$,

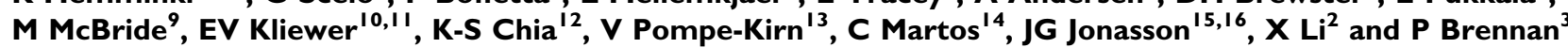 \\ 'Division of Molecular Genetic Epidemiology, German Cancer Research Center (DKFZ), Im Neuenheimer Feld 580, Heidelberg D-69I 20, Germany; \\ ${ }^{2}$ Department of Biosciences at Novum, Karolinska Institute, Huddinge, Sweden; ${ }^{3}$ International Agency for Research on Cancer (IARC), Lyon, France; \\ ${ }^{4}$ Institute of Cancer Epidemiology, Danish Cancer Society, Copenhagen, Denmark; ${ }^{5}$ Central Cancer Registry, Woolloomooloo, New South Wales, Australia; \\ ${ }^{6}$ The Cancer Registry of Nonway, Oslo, Nonway; ${ }^{7}$ Scottish Cancer Registry, Information Services, NHS National Services Scotland, Edinburgh, Scotland; \\ ${ }^{8}$ Finnish Cancer Registry, Institute for Statistical and Epidemiology Cancer Research, Helsinki, Finland; ${ }^{9}$ Cancer Control Research Programme, British \\ Columbia Cancer Registry, Vancouver, BC, Canada; ${ }^{10}$ Epidemiology and Cancer Registry, CancerCare Manitoba, Winnipeg, Canada; "Community Health \\ Sciences, University of Manitoba, Winnipeg, Canada; ${ }^{12}$ Singapore Cancer Registry, Singapore; ${ }^{13}$ Cancer Registry of Slovenia, Institute of Oncology, \\ Ljubljana, Slovenia; ${ }^{14}$ Cancer Registry of Zaragoza, Health Department of Aragon Government, Zaragoza, Spain; ${ }^{15}$ Icelandic Cancer Registry, Icelandic \\ Cancer Society, Reykjavik, Iceland; ${ }^{16}$ Faculty of Medicine, University of Iceland, Reykjavik, Iceland
}

An international multicentre study of first and second primary neoplasms associated with male breast cancer was carried out by pooling data from 13 cancer registries. Among a total of 3409 men with primary breast cancer, 426 (12.5\%) developed a second neoplasia; other than breast cancer, a 34\% overall excess risk of second primary neoplasia, affecting the small intestine (standardised incidence ratio, 4.95, 95\% confidence interval, I.35-12.7), rectum (I.78, I.20-2.54), pancreas (I.93, I.I4-3.05), skin (nonmelanoma, $1.65,1.16-2.29)$, prostate $(1.61,1.34-1.93)$ and lymphohaematopoietic system $(1.63,1.12-2.29)$. A total of 225 male breast cancers was recorded after cancers other than breast cancer, but an increase was found only after lymphohaematopoietic neoplasms. BRCA2 (and to some extent BRCA I) mutations may explain the findings for pancreatic and prostate cancers. Increases at other sites may be related to unknown factors or to chance. This large study shows that the risks for second discordant tumours after male breast cancer pose only a moderate excess risk.

British Journal of Cancer (2005) 92, 1288 - 1292. doi:10.1038/sj.bjc.6602505 www.bjcancer.com

Published online 29 March 2005

(c) 2005 Cancer Research UK

Keywords: subsequent malignancy; cancer registry; pooled analysis; BRCA in men; discordant sites

It is well established that women with a first primary breast cancer run a 2-5-fold increased risk of developing second primary breast cancer compared with the risk for the first primary breast cancer (Chen et al, 1999; Vaittinen and Hemminki, 2000). In men, the risk of second breast cancer after a first breast cancer is much higher, of the order of 100 (Dong and Hemminki, 2001; Auvinen et al, 2002), despite the overall pathology, natural history and hormonal risk factors for sporadic and familial breast cancers showing certain similarities for both genders; socioeconomic risk factors also appear similar for male and female breast cancers (Hsing et al, 1998; Hemminki and Li, 2003; Hemminki et al, 2003b). Klinefelter syndrome, gynaecomastia and testicular disease are additional male risk factors (Hultborn et al, 1997; Lynch et al, 1999). Heritable mutations predisposing to male breast cancer include $B R C A 2, B R C A 1$ and, possibly, the androgen receptor gene (Lynch et al, 1999; Liede et al, 2004). Accounting for some $15 \%$ of all cases, $B R C A 2$ mutations are the most common heritable factors in male breast cancer, and, in addition to breast cancer, carriers have an

*Correspondence: Dr K Hemminki, Division of Molecular Genetic Epidemiology, German Cancer Research Center (DKFZ), Im Neuenheimer Feld 580, Heidelberg D-69120, Germany;

E-mail: k.hemminki@dkfz.de

Received 22 November 2004; revised 7 February 2005; accepted 9 February 2005; published online 29 March 2005 increased risk of prostate, pancreatic and stomach cancers and melanomas (Liede et al, 2004). BRCA1 mutations are less common in male than female breast cancer, and also affect prostate cancer (Liede et al, 2004). Few studies have assessed the risk of second cancers, other than breast cancer, among male breast cancer patients and melanoma appears to the be the only tumour showing an excess among men (Auvinen et al, 2002; Hemminki and Granstrom, 2002).

In the present study, the risks of second primary neoplasms for first male breast cancer, and for male breast cancer following any other cancer are based on pooled data from 13 large cancer registries, which are collaborating in studies on second primary neoplasms. As a result, the study is two times larger than the previous largest study (Auvinen et al, 2002). Since concordant (breast-breast) first and second primaries are not registered in all centres, we do not report on such cancers.

\section{SUBJECTS AND METHODS}

An international multicentre study of second primary cancers has been initiated among second primary cancers. It is a collaboration of large cancer registries operating for at least 25 years including British Columbia, Manitoba and Saskatchewan (Canada), Singapore, Slovenia, Norway, Denmark, Scotland, New South Wales (Australia), Sweden, Finland, Iceland and Zaragoza (Spain). Data were 
provided from each cancer registry on all initial primary cancers including age and sex of the subject, diagnosis and date of the first primary, follow-up for mortality and date and diagnosis of the second primary, if any. Information was also obtained from each cancer registry on the set of rules used for defining a second primary cancer. As these differ between cancer registries, and also over time, the International Association of Cancer Registries (IACR)/International Agency for Research on Cancer (IARC) rules on second primary cancers were adopted as a common set of rules (Muir and Percy, 1991). Tumours were included according to the recording practice of the participating centres, for example, including histologically benign tumours of the central nervous system and carcinoids at any sites. Nonmelanoma skin cancer includes $53.9 \%$ basal and $46.1 \%$ squamous cell carcinomas and other tumours; as second cancers, the proportion of these types is 49.6 and $50.4 \%$, respectively. This was possible as all participating cancer registries currently use the IACR/IARC rules, or a local set of more extensive or detailed rules. The Swedish data have been used in a previous study of male breast cancer (Dong and Hemminki, 2001).

The follow-up time varied according to the available data from the different registries. The follow-up time was longest, $1943-$ 1997, for the Danish and shortest, 1978-1998, for the Spanish data. Observed numbers of male neoplasms were compared to the expected number derived from the age, sex and calendar periodspecific cancer incidence rates in each of the cancer registries. Standardised incidence ratios (SIR) adjusted for age, year and registry were calculated using indirect standardisation methods. Exact confidence intervals (CI) around the SIR were calculated assuming a Poisson distribution for the observed number of neoplasms. As a second type of analysis, we have calculated the SIR for male breast cancer as a second primary after all other cancer sites as a first primary.

\section{RESULTS}

The numbers of men diagnosed with a first primary breast cancer are shown in Table 1 by various characteristics. A total of 3409 men was diagnosed, and of these $426(12.5 \%)$ subsequently developed a second primary neoplasm. More than half of all men were over 65 years at diagnosis, as many as $25 \%$ were diagnosed before year 1975, and the most common follow-up period was 1-4 years $(41.1 \%$ of all men).

The SIRs for second neoplasms by length of follow-up are shown in Table 2 for sites for which at least four cases were recorded in the overall analysis. In the overall analysis, all malignancies were increased by $34 \%$. The highest SIRs were found for small intestine (4.95) and myeloid leukaemia (3.42); among small intestinal tumours, two were carcinoids, one was carcinoma and another one was histologically unspecified. Other specific sites of increased SIRs were the rectum (1.78), pancreas (1.93), (nonmelanoma) skin (1.65) and prostate (1.61). Nonmelanoma skin tumours were in excess only in the short follow-up period, $<12$ months after breast cancer; liver cancer and leukaemias were increased only in the middle follow-up period (1-9 years); pancreatic cancer was only increased in the longest follow-up period $(10+$ years $)$. Only prostate cancer was increased in two follow-up periods.

The effect of diagnostic age for breast cancer on the risk of subsequent neoplasms was analysed in Table 3. Stomach, pancreatic and lung cancers were in excess among relatively young breast cancer patients (diagnosed below age 56 years); larynx cancer was increased in those diagnosed between 56 and 65 years. The SIR for small intestinal cancer was 11.5 in males diagnosed at 66-74 years. Rectal and skin cancers were increased in old breast cancer patients. For leukaemias, the histological type changed by diagnostic age of breast cancer: myeloid leukaemia was in excess in younger patients, whereas among subjects aged $>75$ years, lymphoid leukaemia was seen in excess.

The effect of the calendar period of breast cancer diagnosis is shown in Table 4. The overall risk of second primary neoplasms was somewhat increasing throughout the study period from 1.29 (before year 1975) to $1.41(1991+)$. An excess of lung cancer was limited to patients diagnosed at $1991+$, whereas skin tumours were detected in those diagnosed in the early years of follow-up.

A total of 225 male breast cancers was recorded after any other neoplasms (data not shown). No increase was found after any individual site; after all lymphohaematopoietic neoplasms, the risk for breast cancer was $1.80(N=18,1.07-2.84)$. An excess of breast cancer was diagnosed less than 12 months after lip cancer (SIR

\begin{tabular}{|c|c|c|c|c|c|c|}
\hline & \multicolumn{4}{|c|}{ Second cancer status ${ }^{a}$} & & \\
\hline & $n$ & $\%$ & $n$ & $\%$ & $\mathbf{n}$ & $\%$ \\
\hline \multicolumn{7}{|c|}{ Age at first cancer registration (years) } \\
\hline$<56$ & 617 & 20.7 & 60 & 14.1 & 677 & 19.9 \\
\hline $56-65$ & 706 & 23.7 & 101 & 23.7 & 807 & 23.7 \\
\hline \multicolumn{7}{|c|}{ Calendar period at first cancer registration } \\
\hline$<1975$ & 740 & 24.8 & 111 & 26.1 & 851 & 25 \\
\hline $1975-1983$ & 721 & 24.2 & 144 & 33.8 & 865 & 25.4 \\
\hline $1984-1990$ & 661 & 22.2 & 102 & 23.9 & 763 & 22.4 \\
\hline $1991+$ & 861 & 28.9 & 69 & 16.2 & 930 & 27.3 \\
\hline \multicolumn{7}{|l|}{ Follow-up period } \\
\hline Total & 2983 & 100 & 426 & 100 & 3409 & 100 \\
\hline
\end{tabular}

${ }^{\mathrm{a} C a n c e r}$ different from the first cancer. 
Table 2 SIR for second malignancy after first male breast cancer by length of follow-up period

\begin{tabular}{|c|c|c|c|c|c|c|c|c|c|c|c|c|}
\hline \multirow{2}{*}{$\begin{array}{l}\text { Cancer sites } \\
\text { (ICD 9th revision) }\end{array}$} & \multicolumn{3}{|c|}{ All } & \multicolumn{3}{|c|}{ Less than 12 months } & \multicolumn{3}{|c|}{ I-9 years } & \multicolumn{3}{|c|}{$10+$ years } \\
\hline & Observed & SIR & $95 \% \mathrm{Cl}$ & Observed & SIR & $95 \% \mathrm{Cl}$ & Observed & SIR & $95 \% \mathrm{Cl}$ & Observed & SIR & $95 \% \mathrm{Cl}$ \\
\hline All malignant (I40-208) & 426 & 1.34 & $(1.22-1.47)$ & 73 & 1.62 & $(1.27-2.03)$ & 264 & 1.31 & $(1.16-1.48)$ & 89 & 1.25 & $(1.01-1.54)$ \\
\hline Oral cavity, pharynx $(140-149)$ & 8 & 0.93 & $(0.40-1.82)$ & I & 0.78 & $(0.02-4.34)$ & 7 & 1.25 & $(0.50-2.57)$ & 0 & & \\
\hline Stomach (15I) & 22 & 1.09 & $(0.68-1.65)$ & 4 & 1.24 & $(0.34-3.18)$ & 12 & 0.92 & $(0.48-1.61)$ & 6 & 1.53 & $(0.56-3.34)$ \\
\hline Small intestine (152) & 4 & 4.95 & $(1.35-12.7)$ & 1 & 8.56 & $(0.21-47.7)$ & 2 & 3.92 & $(0.47-14.2)$ & I & 5.54 & $(0.14-$ \\
\hline Rectum (I54) & 30 & 1.78 & $(1.20-2.54)$ & 6 & 2.48 & $(0.91-5.40)$ & 21 & 1.96 & $(1.21-3.00)$ & 3 & 0.80 & $(0.16-2.33)$ \\
\hline $\begin{array}{l}\text { Liver, gallbladder, bile ducts } \\
\text { (155- | } 56 \text {, excluding | } 55.2 \text { ) }\end{array}$ & 6 & 1.07 & $(0.39-2.33)$ & 0 & & & 6 & 1.70 & $(0.62-3.70)$ & 0 & & \\
\hline Liver (155, excluding |55.2) & 6 & 1.85 & $(0.68-4.02)$ & 0 & & & 6 & 2.95 & $(1.08-6.41)$ & 0 & & \\
\hline Pancreas (157) & 18 & 1.93 & $(1.14-3.05)$ & 4 & 2.97 & $(0.81-7.59)$ & 8 & 1.35 & $(0.58-2.65)$ & 6 & 2.95 & $(1.08-6.43)$ \\
\hline Larynx (|6|) & 7 & 1.80 & $(0.73-3.72)$ & I & 1.73 & $(0.04-9.66)$ & 4 & 1.59 & $(0.43-4.08)$ & 2 & 2.53 & $(0.31-9.16)$ \\
\hline Lung (162) & 63 & 1.26 & $(0.96-1.61)$ & 9 & 1.21 & $(0.55-2.30)$ & 39 & 1.21 & $(0.86-1.65)$ & 15 & 1.44 & $(0.81-2.37)$ \\
\hline Lymphohaen & 33 & 1.63 & $(1.12-2.29)$ & 5 & 1.76 & $(0.57-4.10)$ & 21 & 1.63 & $(1.01-2.50)$ & 7 & 1.54 & $(0.62-3.18)$ \\
\hline Lymphomas $(200-202)$ & 11 & 1.33 & $(0.66-2.37)$ & I & 0.87 & $(0.02-4.84)$ & 6 & 1.14 & $(0.42-2.47)$ & 4 & 2.14 & $(0.58-5.48)$ \\
\hline Non-Hodgkin's lymphoma & 11 & 1.46 & $(0.73-2.62)$ & । & 0.97 & $(0.02-5.42)$ & 6 & 1.26 & $(0.46-2.74)$ & 4 & 2.33 & $(0.64-5.97)$ \\
\hline 200,202$)$ & & & & & & & & & & & & \\
\hline Multiple myeloma (203) & 5 & 1.18 & $(0.3$ & 2 & 3.36 & $(0.41-12.1)$ & 3 & 1.12 & $(0.2-2$ & 0 & & \\
\hline$(204-208)$ & 17 & 2.21 & $(1.29-3.54)$ & 2 & 1.81 & $(0.22-6.55)$ & 12 & 2.45 & $(1.27-4.28)$ & 3 & 1.78 & $(0.3$ \\
\hline ía (204) & 7 & 1.86 & $(0.75-3.83)$ & 0 & & & 6 & 2.51 & $(0.92-5.45)$ & I & 1.21 & $(0.03-6.76)$ \\
\hline Myeloid leukaemia (205) & 8 & 3.42 & $(1.47-6.73)$ & I & 3.02 & $(0.08-16.8)$ & 6 & 3.98 & $(1.46-8.67)$ & I & 1.98 & $(0.05-11.0)$ \\
\hline
\end{tabular}

$\mathrm{SIR}=$ standardised incidence ratios; $\mathrm{Cl}=$ confidence interval; ICD = International Classification of Diseases. Bold numerals show that $95 \% \mathrm{Cl}$ does not include 1.00

Table 3 SIR for second malignancy after first male breast cancer diagnosed at different ages

\begin{tabular}{|c|c|c|c|c|c|c|c|c|c|c|c|c|}
\hline \multirow{2}{*}{ Cancer sites (ICD 9th revision) } & \multicolumn{12}{|c|}{ Age at first cancer registration (years) } \\
\hline & \multicolumn{3}{|c|}{$<56$} & \multicolumn{3}{|c|}{$56-65$} & \multicolumn{3}{|c|}{$66-74$} & \multicolumn{3}{|c|}{$75+$} \\
\hline All malignant (| 40-208) & 60 & 1.62 & $(1.23-2.08)$ & 101 & 1.18 & $(0.96-1.43)$ & 152 & 1.39 & $(1.18-1.63)$ & 113 & 1.32 & $(1.09-1.58)$ \\
\hline Oral cavity, pharynx $(140-149)$ & 3 & 1.94 & $(0.40-5.66)$ & 3 & 1.11 & $(0.23-3.25)$ & । & 0.38 & $(0.01-2.13)$ & । & 0.56 & $(0.01-3.13)$ \\
\hline Stomach $(15 \mid)$ & 7 & 3.82 & $(1.54-7.87)$ & । & 0.20 & $(0.00-1.11)$ & 12 & 1.64 & $(0.85-2.87)$ & 2 & 0.34 & $(0.04-1.21)$ \\
\hline Colon (I53) & I & 0.40 & $(0.01-2.20)$ & 5 & 0.82 & $(0.26-1.90)$ & 9 & 1.10 & $(0.50-2.09)$ & 10 & 1.44 & $(0.69-2.64)$ \\
\hline Rectum (I54) & 4 & 1.97 & $(0.54-5.06)$ & 7 & 1.49 & $(0.60-3.08)$ & 7 & 1.21 & $(0.49-2.50)$ & 12 & 2.72 & $(1.41-4.76)$ \\
\hline $\begin{array}{l}\text { Liver, gallbladder, bile ducts ( } 155 \text { - } \\
\text { 156, excluding } 155.2 \text { ) }\end{array}$ & 0 & & & 2 & 1.30 & $(0.16-4.69)$ & 2 & 1.02 & $(0.12-3.70)$ & 2 & 1.36 & $(0.16-4.92)$ \\
\hline Liver ( 155 , excluding 155.2) & 0 & & & 2 & 2.16 & $(0.26-7.82)$ & 2 & 1.77 & $(0.21-6.38)$ & 2 & 2.52 & $(0.30-9.11)$ \\
\hline Pancreas (157) & 5 & 4.66 & $(1.51-10.9)$ & 6 & 2.42 & $(0.89-5.27)$ & 5 & 1.54 & $(0.50-3.59)$ & 2 & 0.79 & $(0.10-2.86)$ \\
\hline Larynx (|6|) & 0 & & & 5 & 3.66 & $(1.19-8.54)$ & 2 & ।.75 & $(0.21-6.32)$ & 0 & & \\
\hline Kidney (| 89 , excluding |89.3, | 89.4) & 3 & 2.24 & $(0.46-6.55)$ & 2 & 0.82 & $(0.10-2.95)$ & 2 & 0.74 & $(0.09-2.66)$ & 0 & & \\
\hline $\begin{array}{l}\text { Lymphohaematopoietic } \\
(200-208)\end{array}$ & 5 & 1.77 & $(0.58-4.14)$ & 9 & 1.65 & $(0.75-3.13)$ & 8 & 1.19 & $(0.5 I-2.35)$ & 11 & 2.10 & $(1.05-3.75)$ \\
\hline Lymphomas (200-202) & 2 & 1.45 & $(0.18-5.25)$ & 2 & 0.86 & $(0.10-3.09)$ & 5 & 1.89 & $(0.6 I-4.4 I)$ & 2 & 1.03 & $(0.12-3.72)$ \\
\hline $\begin{array}{l}\text { Non-Hodgkin's lymphoma } \\
(200,202)\end{array}$ & 2 & 1.68 & $(0.20-6.06)$ & 2 & 0.95 & $(0.12-3.44)$ & 5 & 2.07 & $(0.67-4.83)$ & 2 & 1.11 & $(0.13-4.01)$ \\
\hline Multiple myeloma (203) & 0 & & & 0 & & & । & 0.68 & $(0.02-3.79)$ & 4 & 3.51 & $(0.96-8.99)$ \\
\hline Leukaemias (204-208) & 3 & 3.24 & $(0.67-9.47)$ & 7 & 3.52 & $(1.42-7.25)$ & 2 & 0.77 & $(0.09-2.77)$ & 5 & 2.31 & $(0.75-5.39)$ \\
\hline Lymphoid leukaemia (204) & I & 2.28 & $(0.06-12.7)$ & 2 & 2.00 & $(0.24-7.23)$ & 0 & & & 4 & 3.78 & $(1.03-9.68)$ \\
\hline Myeloid leukaemia (205) & I & 3.50 & $(0.09-19.5)$ & 4 & 6.53 & $(1.78-16.7)$ & 2 & 2.50 & $(0.30-9.03)$ & I & 1.55 & $(0.04-8.65)$ \\
\hline
\end{tabular}

$\mathrm{SIR}=$ standardised incidence ratios; $\mathrm{Cl}=$ confidence interval; $\mathrm{ICD}=$ International Classification of Diseases. Bold numerals show that $95 \% \mathrm{Cl}$ does not include 1.00 . 
Table 4 SIR for second malignancy after first male breast cancer diagnosed at different periods

Period at first cancer registration

\begin{tabular}{lrr|}
$<1975$ & $1975-1983$ & $1984-1990$
\end{tabular}

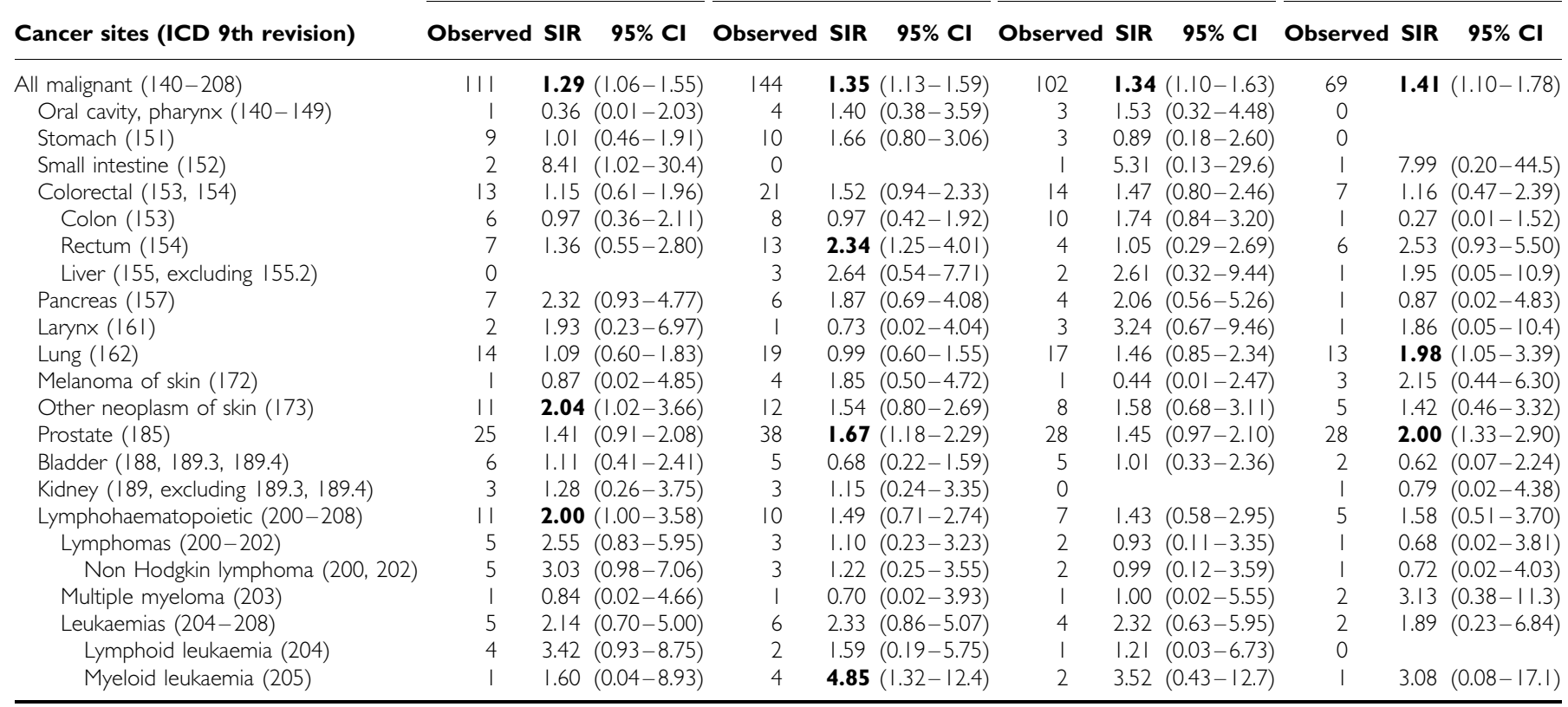

$\mathrm{SIR}=$ standardised incidence ratios; $\mathrm{Cl}=$ confidence interval; $\mathrm{ICD}=$ International Classification of Diseases. Bold numerals show that $95 \% \mathrm{Cl}$ does not include 1.00 .

$5.37, N=3,1.11-15.7)$. Breast cancer was also increased $1-9$ years after prostate cancer (SIR $1.45, N=48,1.07-1.92$ ) and after multiple myeloma (SIR 3.77, $N=4,1.03-9.65$ ). There was no overall increase in breast cancer after prostate cancer (SIR 1.19, $N=56,0.90-1.54)$.

\section{DISCUSSION}

In order to interpret the results of the present study, we need to consider the treatment options that have been available throughout the study period. In general, therapies for male breast cancer have been adopted from female breast cancer, and surgery and radiotherapy, usually in combination, have been the main treatments throughout the study period (Buzdar, 2003; Gennari et al, 2004) with chemotherapy increasing towards the end.

The present data should be of high quality, as they were carefully controlled by the participating, well-established cancer registries. These pooled data are the largest data set used for the study of male breast cancer. Nevertheless, chance associations consequent on the multiple comparisons may be present and the findings should be considered tentative.

The finding that two cancers were increased after each other, irrespective of the order would represent suggestive evidence. For example, non-Hodgkin's lymphoma is increased after squamous cell carcinoma of the skin in men and women, and a similar association has been observed in the reverse order (Hemminki et al, 2003a). Such a broad internal control is, however, usually possible only for reasonably common malignancies of both genders with good survival and reasonably similar age distributions. In the present study, prostate cancer was increased after breast cancer, and breast cancer was increased after prostate cancer; however, only in one follow-up period. BRCA2 (and to some extent BRCA1) mutations could explain these findings. Among other BRCA2-related male tumours, pancreatic cancer showed a high risk after breast cancer (overall SIR 1.93) and stomach cancer was increased in men who were diagnosed with breast cancer before the age of 56 years; however, no increase was observed for melanoma in contrast to findings from the SEER study (Auvinen et al, 2002; Hemminki and Granstrom, 2002).

Radiotherapy and many chemotherapy agents cause DNA damage, which may be related to the risk of subsequent neoplasms. A trend with an increasing relative risk with follow-up time would provide evidence for a relation between therapy for the primary cancer and the risk of a second cancer in the present study (Swerdlow et al, 2000). However, there was no increasing relative risk with follow-up time for any neoplasm following male breast cancer. Leukaemia risks were above unity throughout the follow-up periods, and they were highest for myeloid leukaemia. The only significant risk for pancreatic cancer was in the last follow-up period, but the SIRs were above unity throughout the follow-up periods; besides, therapy-induced pancreatic cancer is probably rare (Swerdlow et al, 2000). An increased risk of nonmelanoma skin cancer was only noted in the first follow-up period, which may be due to surveillance effects or immunological disturbances.

The sites at which increased overall SIRs were noted and which were not related to the above conditions included the small intestine and rectum. Increased SIRs were additionally noted for liver, lung and laryngeal cancers and for multiple myeloma, when a specific follow-up period or diagnostic age was considered. There are no obvious common environmental risk factors for these neoplasms. Some of the small intestinal tumours were carcinoids and these types of tumours are often diagnosed incidentally and more often among individuals with high socioeconomic status (Hemminki and Li, 2001). The involvement of sites in the same organ systems, gastrointestinal tract and respiratory system may add some credibility to the findings.

The relative increase in all second neoplasms (breast excluded) was a moderate 1.34 , in marked contrast to second breast cancer, which can be up to 100 (Auvinen et al, 2002; Hemminki and 
Granstrom, 2002). However, as male breast cancers are rare, the modest excess risk of second prostate cancer may amount to equally many excess cases as second breast cancer. Excess cases are also found for pancreatic and nonmelanoma skin tumours and for leukaemias.

\section{REFERENCES}

Auvinen A, Curstis R, Ron E (2002) Risk of subsequent cancer following breast cancer in men. J Natl Cancer Inst 94: 1330 - 1332

Buzdar A (2003) Breast cancer in men. Oncology 17: 1361-1364

Chen Y, Thompson W, Semenciw R, Mao Y (1999) Epidemiology of contralateral breast cancer. Cancer Epidemiol Biomarkers Prev 8: 855-861

Dong C, Hemminki K (2001) Second primary breast cancer in men. Breast Cancer Res Treat 66: $171-172$

Gennari R, Curigliano G, Jereczek-Fossa BA, Zurrida S, Renne G, Intra M, Galimberti V, Luini A, Orecchia R, Viale G, Goldhrisch A, Veronesi U (2004) Male breast cancer: a special therapeutic problem. Anything new? [review]. Int J Oncol 24: 663-670

Hemminki K, Granstrom C (2002) Re: Risk of subsequent cancer following breast cancer in men. J Natl Cancer Inst 94: 1892

Hemminki K, Jiang Y, Steineck G (2003a) Skin cancer and non-Hodgkin's lymphoma as second malignancies: markers of impaired immune function? Eur J Cancer 39: 223 - 229

Hemminki K, Li X (2001) Incidence trends and risk factors of carcinoid tumors. Cancer 92: 2204-2210

Hemminki K, Li X (2003) Level of education and the risk of cancer in Sweden. Cancer Epidemiol Biomarkers Prev 12: 796-802

Hemminki K, Zhang H, Czene K (2003b) Socioeconomic factors in cancer in Sweden. Int J Cancer 105: $692-700$

\section{ACKNOWLEDGEMENTS}

We acknowledge the work of Didier Colin, IARC, for initial preparation of the data set. The analysis was supported by a R03 grant to IARC by the US NCI.

Hsing AW, McLaughlin JK, Cocco P, Co Chien HT, Fraumeni Jr JF (1998) Risk factors for male breast cancer (United States). Cancer Causes Control 9: 269-275

Hultborn R, Hanson C, Kopf I, Verbiene I, Warnhammar E, Weimarck A (1997) Prevalence of Klienefelter's syndrome in male breast cancer patients. Anticancer Res 17: $4293-4297$

Liede A, Karlan BY, Narod SA (2004) Cancer risks for male carriers of germline mutations in BRCA1 or BRCA2: a review of the literature. J Clin Oncol 22: $735-742$

Lynch H, Watson P, Narod S (1999) The genetic epidemiology of male breast carcinoma. Cancer 86: 244-246

Muir C, Percy C (1991) Classification and coding of neoplasms. In Cancer Registration: Priciples and Methods Jensen O, Parkin D, MacLennan R, Muir C, Skeet R (eds) Vol. 95, pp 64-81. Lyon: IARC Science Publications

Swerdlow A, Barber J, Hudson G, Cunningham D, Gupta R, Hancock B, Horwich A, Lister T, Linch D (2000) Risk of second malignancy after Hodgkin's disease in a collaborative British cohort: the relation to age at treatment. J Clin Oncol 18: 498-509

Vaittinen P, Hemminki K (2000) Risk factors and age-incidence relationships for contralateral breast cancer. Int $J$ Cancer 88: 998- 1002 